\title{
Addressing the greenhouse gas emissions associated with food distribution: a case study of Californian farmers' markets
}

\author{
Susan Cholette*
}

\section{Introduction}

Mainstream American consumers are becoming more concerned about the sources of their food and have started to show interest in locally produced food. Such foods, especially produce, are perceived to be healthier, tastier, and both socially and environmentally friendlier than foodstuffs from distant large scale producers. Likewise, farmers can often obtain significant price premiums. Such benefits have been thoroughly documented by others, including Brown (2002), Kremen et al. (2004) and Hunt (2007). While the definition of "local" varies, and the consumer perception of its boundaries is the subject of academic research (Giovannuci et al., 2010), it is clear that this food category is experiencing rapid sales growth. The emerging dynamic of localization is occurring in many countries; for example Brunoni et al. (2007) document how Italian farmers' markets have grown and how consumers have become more discerning and involved in purchasing foods. On the other side of the globe, Guthrie et al. (2003) depict New Zealand's burgeoning farmers markets. Yet it may surprise some that the nation that popularized the frozen TV dinner is experiencing rapid growth within the category of local food; an industry study (Porjes, 2007) estimates this category, worth 4 billion dollars United States in 2002, is expected to grow to 7 billion dollars by 2011. Once the purview of health food stores, local foods are appearing everywhere; Wal-Mart has announced a local sourcing initiative for their produce, and even institutional U.S. food providers such as hospitals and prisons are creating menus with such products (Hardesty, 2008).

\footnotetext{
* Department of Decision Sciences, San Francisco State University.
} 
Just over nine tenths of U.S. farms are classified as "small family farms" with annual sales below $\$ 250,000$, and such farms produce approximately one quarter of national agricultural output (USDA, 2005). These small businesses face daunting economies of scale issues within the food supply chain, especially those that compete directly with the $10 \%$ of the farms which produce the other three-fourths of total U.S. agricultural output! While some large retailers do buy from smaller farms, Cantor \& Strochlic (2009) claim entry barriers are substantial, and small to midsized farms often have had more success with selling directly to the consumer. Just as Brunori et al. (2009) discuss how small Tuscan farmers have been able to establish niches in selling directly to the consumer, many of their U.S. counterparts have developed direct-to-consumer channels: providing roadside stands or pick-your-own fields, sourcing to Community Supported Agriculture (CSA) subscribers and attending farmers' markets. Farmers' markets are the most common direct channel in the U.S.; Cantor \& Strochlic (2009) survey farmers, finding 69\% of respondents attend such markets. Zepeda \& Reid (2004) emphasize that farmers' markets are the channel of choice for most consumers, as other direct channels require greater consumer involvement.

In this case study we consider California, the leading U.S. State for both the number of farmers' markets and the concentration of small farms (Cantor \& Strochlic, 2009). Farmers' markets were established in California in 1977, when state law permitted farmers to sell at a state certified farmers' markets without additional packaging or labeling (Certified Farmers Market Program, 2011). A farmers' market authority verifies that the farmer is from California and is the primary producer; California follows a 'producer only model' and disallows resellers. According to the USDA (2011), as of 2010 the U.S. hosted 6132 farmers' markets, a tripling from 1994. The importance of this channel is showcased in their survey results, which finds that sales at farmers markets totaled over $\$ 1$ billion in 2005 and that more than a quarter of vendors at the surveyed markets derived all farm income from these markets (USDA, 2011). In California alone, approximately 2,200 certified producers attend 700 certified farmers' markets, half of which occur regularly throughout the year (Certified Farmers Market Program, 2011).

The proliferation in these markets might seem a blessing for farmers, who would appear to have more opportunity to reach consumers. However, reality is more complex. Along with the number of markets, the competition from other vendors has also increased. Farmers from any part of California can attend any market in state, and in recent years more farmers are traversing greater distances. Worthen (2010) reports that the increase in markets has resulted in lower profits for many farmers, who report having to make more trips to sell the same amount of product as in prior years. Worthen (2010) 
interviews a few farmers who often do not make enough money to cover the costs of attending multiple markets.

One of the culprits is geography. California is a large state with the majority of farms and farmers' markets well separated from each other. This distribution is illustrated in Figure 1, which depicts a representative subset of farmers' markets and certified participating farms that service them. The populous and affluent Bay Area and Los Angeles metropolitan areas provide the densest concentration of farmers' markets, and the majority of farms are found near the Central Valley, a fertile but sparsely populated and poorer region.

\section{Fig. 1 - Subset of California Farmers' Markets and Participating Farms}

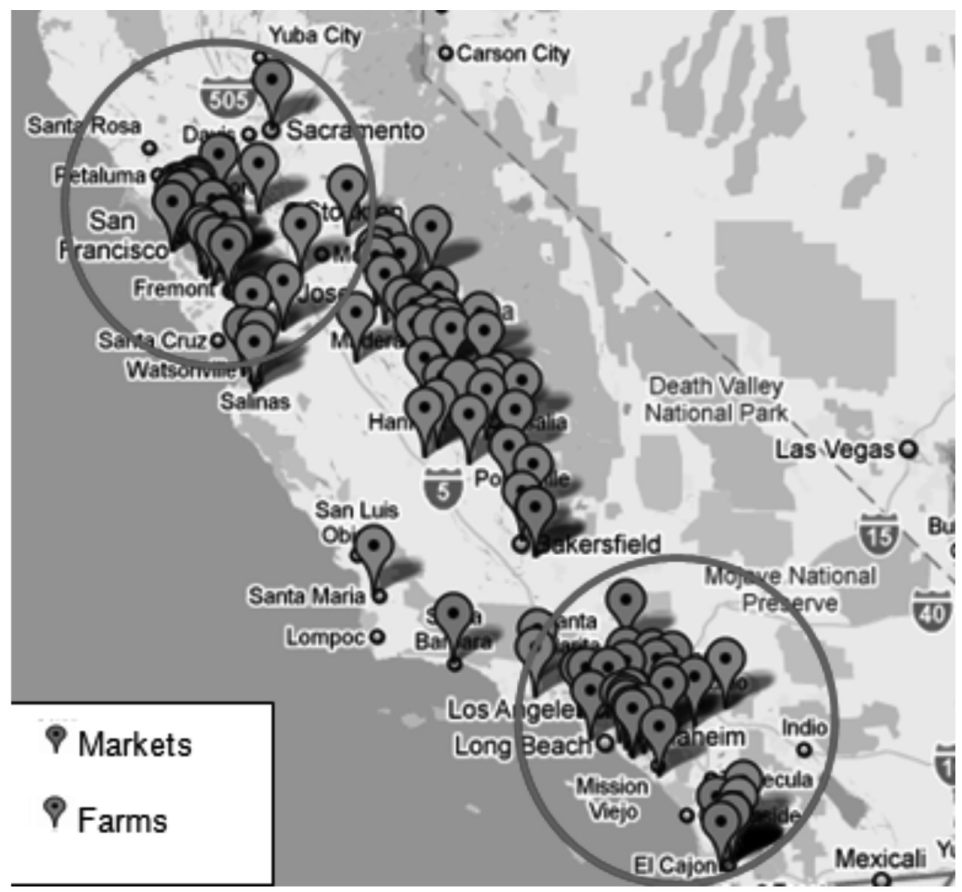

Source: Jog (2010)

Cantor \& Strochlic (2009) survey producers with respect to their difficulties, finding a major complaint concerns the distances to the profitable farmers' markets; these large distances preclude greater participation and limit profits for those who do attend. In their argument in support of shopping at farmers' markets, CUESA (2009) profiles different types of 
produce vendors at the San Francisco Ferry Plaza Farmers' Market, showing average one-way travel ranges between $100 \mathrm{~km}$ to $300 \mathrm{~km}$. Yet distances such as these are considerable.

The Pacific Coast Farmers' Market directory (PCFMA, 2011) provides insight onto the reach of many farms; for example, Schletewitz Farms, a third generation fruit and tomato producer located in Sanger, a community in the Sierra foothills. They frequent several Bay Area farmers' markets, including 5 that occur weekly throughout the year in Belmont, Cupertino, Pleasanton, San Francisco, and San Mateo. Assuming separate trips are necessary for each market visit, the total round trip weekly distances sum to approximately 3000 $\mathrm{km}$. Furthermore, they visit several other markets when more of their fruits are in season, such as the Palo Alto's Farmers' Market (PA Market, 2011). We also consider the market perspective. Jog (2010) inventories the vendors at Jack London Square farmers' market, a year-round Sunday market in Oakland, and reports that some hail from as far as San Diego, over $750 \mathrm{~km}$ away.

Such distances are not always insurmountable, but small farmers do not enjoy the economies of scale available to larger producers. Typically these farmers drive smaller vehicles such as pick-up trucks, and each trip to a market entails a separate journey. These distances not only serve as market barriers and increase overall costs but also create another problem. When considered on a per unit basis, even moderate distances travelled in low capacity vehicles result in a comparatively high rate of energy usage and corresponding greenhouse gas emissions. Such transportation inefficiencies contribute to what is commonly called the carbon footprint. While there may be many benefits from purchasing and consuming farmers' market produce compared to that imported from distant large-scale farms, we shall see that a lower carbon impact is not one of them.

The remainder of this paper is organized as follows. We quantify this problem further, providing context and summarizing the contributions of other researchers. We restrict our focus to that of Californian farmers selling direct to consumers via famers' markets. With the help of analytical software, we model the outbound logistics associated with produce distribution to Northern California farmers' markets. We compare scenario results and show how different supply chain configurations can impact emissions. We propose a solution that would result in significant savings. Lastly, we suggest directions for future research.

\section{Problem Delineation and Literature Review}

Many researchers such as Hunt (2007) and Conner et al. (2009) document the benefits of farmers' markets, and others such as Brown (2002) and Alonso 
and O'Neill (2011) consider surveys that measure consumers' motivation for shopping at such markets. Further market research is performed by Govindasamy et al. (2002), Darby et al. (2008) and Carpio \& IsengildinaMassa (2009); these researchers investigate consumers' willingness to pay price premiums, finding that producers can indeed earn higher prices at the farmers' market. Govindasamy et al. (2003) survey the other side of the stalls, finding that most producers are satisfied with farmers' markets as sales channels. While these are worthy subjects for investigation and serve to emphasize that farmers' markets are more than a passing fad, we shall consider a different aspect of sustainability; that of environmental sustainability.

While a full lifecycle analysis (LCA) for most agricultural products entails evaluation of many different environmental and even social indicators, this paper focuses solely on energy usage and resultant greenhouse gas emissions as measured in carbon dioxide equivalents, $\mathrm{CO}_{2} \mathrm{e}$. Narrow though it may be, this sub-category of environmental impact deserves attention. Heller \& Keoleian (2000) estimate that transportation, namely diesel fuels from trucking, accounts for a quarter of the energy consumed within the U.S. food system. Pirog et al. (2001) report that nearly half of all fruit sold in the United States is imported and that produce grown in North America travels an average of 2000 kilometers from source to point of sale. Akkerman et al. (2010) model a food distribution network, balancing sustainability with food quality and safety concerns. Marquez et al. (2010) perform detailed carbon audits of the transport of produce. Given the predominant use of fossil fuels in transport, high energy usage is synonymous with large greenhouse gas emissions. Although energy usage and greenhouse gas emissions are different entities, they are highly correlated in practice. Unless we are switching to a different fuel stock, such as derived from solar or wind energy, increasing energy intensity leads to greater greenhouse gas emissions. In the remainder of this paper, we effectively equate energy usage with emissions.

We first consider others who investigate the link between food and energy/emissions. Energy usage varies greatly between food types; Weber \& Matthews (2008) calculate that food transportation may account for half of total $\mathrm{CO}_{2} \mathrm{e}$ emissions for many fruits and vegetables but less than $10 \%$ for red meat products. Production methods may impact energy and emissions even for the same types of food. While the metric of food miles has gained the attention of the popular press and some researchers, such as Pirog et al. (2001), consideration only of distances travelled can be misleading. CarlssonKanyama et al. (2003) study Swedish tomatoes, finding those produced locally in greenhouses require 10 times the energy as field-grown tomatoes imported from Southern Europe. Saunders and Barber (2007) find that milk solids produced for local use in the United Kingdom generate over a third more emissions than the same product from New Zealand, despite long- 
distance transport requirements. This result reflects the more energy-intensive dairy production system in the United Kingdom. Milà i Canals et al. (2007) note that yield losses from long term storage can lead to imported apples having a lower overall emissions profile than local apples harvested and stored for several months. All of these studies showcase surprising results to those who might expect distance to dominate in emissions calculations.

One of the reasons that long distance food supply chains are often more energy efficient has to do with economies of scale. Van Hauwermeiren et al. (2007) demonstrate that organically grown food is not necessarily more carbon efficient than its conventional counterpart. Schlich \& Fleissner (2005) provide examples of how the international sourcing of some food products can be less energy intensive on a per-unit basis than the local (German) equivalent and posit the existence of an "ecology of scale". For example, Brazil's climate is naturally more conducive to fruit production than most European climates, and Brazilian juice production occurs on a much large scale than is supported in Europe. Consequently, Schlich \& Fleissner (2005) calculate that the lower emissions due to producing in juice in Brazil more than offset the emissions associated with transporting the juice to Europe.

Coley et al. (2009) compare the carbon emissions associated with the supply chain for food purchases at a U.K. supermarket to those associated with a hypothetical small local farm shop. They set the frame as postproduction at the farm all the way to the customer's home and consider that the supermarket may offer a home delivery service. In a detailed carbon audit, they find that the former is substantially more energy efficient per box of goods delivered than the latter. While some might argue with last stage differentiation between these two supply chains, Coley et al. (2009) show that even when the frame is adjusted to be cradle-to-gate, the operational savings realized by the supermarket distribution system render it more energy and emissions efficient.

In their study of the U.S. dairy industry, Nicholson et al. (2011) lament that, despite growing interest in localizing the food supply chain, few professionals have studied the costs associated with localization. They create a transshipment model to analyze a multiple stage supply chain for different products, some of which serve both as finished goods and as intermediate inputs for other products. They find that minimizing distance travelled is not the most cost-effective solution, due to increased inefficiencies. Furthermore, in such a scenario, consumers would bear these cost increases unequally within different regions. Although they focus on costs, it is clear from the context that their findings would likely apply to emissions.

Not all such publications are academic in nature. In a government-funded study intended to guide investment and public policy, Cantor \& Strochlic (2009) analyze the barriers that small and medium sized organic farmers face 
in all sales channels. They find the dominant problems are: managing volumes, getting access to appropriate markets, and competing on a cost basis with larger scale farmers or otherwise earning an appropriate price premium. While Cantor \& Strochlic (2009) report that farmers are concerned with the over proliferation of farmers' markets, their proposal with respect to this sales channel involves a limited solution focusing on education, regulation and labeling. Likewise, King et al. (2010) in their EPA-funded case studies of local food sourcing find that the total energy used per unit of product is more closely related to supply chain structure and size than to the distance food must travel. Additionally, they note that although farmers retain most of the retail price in direct-to-consumer channels such as farmers' markets, the costs associated with bringing products to market can range between $13 \%$ to over $60 \%$ of this price, reducing the viability of selling in such markets. They also investigate some intermediated sales channels, such as cooperative retail stores.

We add to this body of literature by considering the case of California farmers selling direct to Farmers' Markets. We quantify the underlying problem and propose a solution that would enable consumers and producers alike to enjoy the best of both worlds: the provision of fresh, locally-sourced produce from family farms to urban consumers with improved costs and decreased emissions resulting from greater system efficiencies.

\section{Research Methodologies and Results}

\subsection{Illustrating the Supply Chain}

We investigate the outbound logistics involved in meeting the demand of a San Francisco consumer who seeks to purchase a kilogram of tomatoes, either at a neighborhood supermarket, Safeway, or a farmers' market. We set the system boundaries as farm to retail gate. From personal experience, we can emphasize that the difficulties and expense of driving and parking in San Francisco encourage shoppers to use public transport or cycle to downtown destinations. We thus avoid the problem that others such as Browne et al. (2005), Cholette and Venkat (2009), and Coley et al. (2009) find with use of a larger frame; namely that the retailer-to-consumer link can be the most energy-intensive and the hardest to measure.

\subsubsection{Initial Scenarios}

We first consider four scenarios. Two scenarios involve sourcing from the previously mentioned Schletewitz Farms. This third-generation small family 
farm provides fruits, including tomatoes, to several Bay Area farmers' markets, per Figure 2. The first scenario starts with a Schletewitz employee driving from Sanger at 2 a.m. (PA Market, 2011) to the weekly market in San Francisco, a significant distance of $320 \mathrm{~km}$. We assume use of a large gasoline-powered pickup truck with no special cooling. Some farmers may use larger vehicles, but the payload of a large pickup truck (with an effective $600 \mathrm{~kg}$ weight limit) is likely the most appropriate for a single trip. For consistency all vehicles in each scenario are assumed to have a 90\% utilization rate and no backhaul, i.e. vehicles return empty.

\section{Fig. 2 - Family Farm at a Farmers' Market}

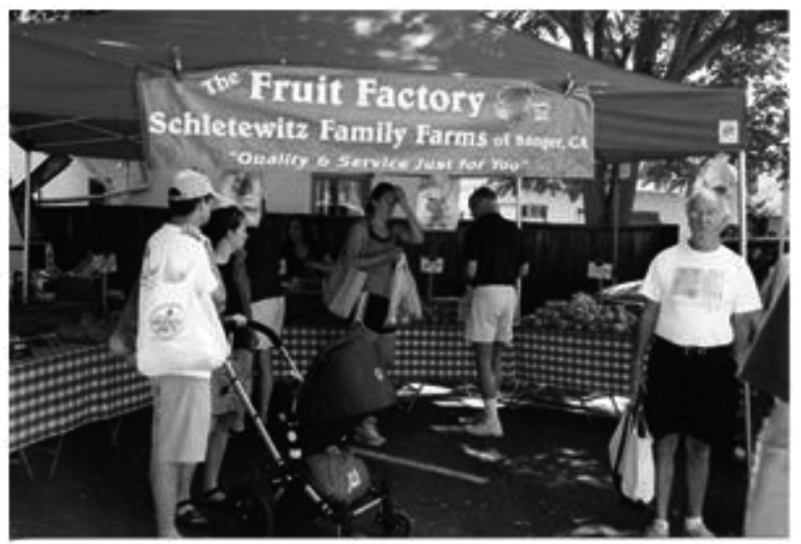

Source: PA Market (2011)

In the second scenario Schletewitz Farms now provides tomatoes to Safeway. According to Safeway's 'Locally Grown' campaign, up to a third of its produce sales are locally sourced, including through partnerships with small regional farms (Greenbiz, 2009). Cantor \& Strochlic (2009) document that small to midsized organic farms have achieved some success with such wholesale sourcing. For this scenario, Schletewitz Farms drives the pickup truck to Safeway's regional distribution center (DC) in Tracy, which is just outside the Bay Area. We assume the product rests in cooled storage at the DC until Safeway restocks the retail stores in San Francisco using their fleet of heavy duty diesel trucks. Given the mixed payload, we assume cooling is needed in transit.

For the third scenario; Safeway buys from a larger, neighboring farm, and this farm's size results a midsized commercial diesel truck being used to bring produce to the Tracy DC. While able to carry over 10 times the weight 
of a large pickup truck, midsized trucks are much smaller than the heavy duty trucks used for interstate transport. For the final scenario we select a different conventional source; importing tomatoes from Mexico via a heavy duty truck. A distance of $2000 \mathrm{~km}$ is more than sufficient to reach Sonora, one of the Mexican states with prolific agricultural output. No matter which farm Safeway sources from, all channel partners deliver to the Tracy DC. The four scenarios are summarized in Table 1, with distances generated by GoogleMaps. ${ }^{\mathrm{TM}}$

\section{Tab. 1 - Distance and Modes Summarized for Initial Scenarios}

\begin{tabular}{|c|c|c|c|c|c|c|c|c|}
\hline & \multicolumn{2}{|c|}{$\begin{array}{l}\text { Local Small Farm } \rightarrow \\
\text { Farmers' Market }\end{array}$} & \multicolumn{2}{|c|}{$\begin{array}{l}\text { Local Small Farm } \rightarrow \\
\text { Safeway Sourcing }\end{array}$} & \multicolumn{2}{|c|}{$\begin{array}{c}\text { Local Larger Farm } \rightarrow \\
\text { Safeway Sourcing }\end{array}$} & \multicolumn{2}{|c|}{$\begin{array}{l}\text { Safeway Sourcing } \\
\text { from Mexico }\end{array}$} \\
\hline & $\begin{array}{l}\text { transport } \\
\text { mode }\end{array}$ & $\begin{array}{l}\text { one-way } \\
\text { distance } \\
(\mathrm{km})\end{array}$ & $\begin{array}{l}\text { transport } \\
\text { mode }\end{array}$ & $\begin{array}{l}\text { one-way } \\
\text { distance } \\
(\mathrm{km})\end{array}$ & $\begin{array}{l}\text { transport } \\
\text { mode }\end{array}$ & $\begin{array}{l}\text { one-way } \\
\text { distance } \\
(\mathrm{km})\end{array}$ & $\begin{array}{l}\text { transport } \\
\text { mode }\end{array}$ & $\begin{array}{l}\text { one-way } \\
\text { distance } \\
(\mathrm{km})\end{array}$ \\
\hline $\begin{array}{r}\text { link \#1: } \\
\text { transport } \\
\text { from the } \\
\text { farm }\end{array}$ & $\begin{array}{l}\text { Large } \\
\text { Pickup } \\
\text { Truck, } \\
\text { Gasoline }\end{array}$ & 320 & $\begin{array}{l}\text { Large } \\
\text { Pickup } \\
\text { Truck, } \\
\text { Gasoline }\end{array}$ & 225 & $\begin{array}{l}\text { Midsize } \\
\text { Truck, } \\
\text { Diesel }\end{array}$ & 225 & $\begin{array}{l}\text { Heavy } \\
\text { duty } \\
\text { Truck, } \\
\text { Diesel }\end{array}$ & 2000 \\
\hline $\begin{array}{r}\text { link \#2: } \\
\text { transport to } \\
\text { the market }\end{array}$ & & $\mathrm{n} / \mathrm{a}$ & $\begin{array}{l}\text { Heavy } \\
\text { duty } \\
\text { Truck, } \\
\text { Diesel, } \\
\text { Cooler }\end{array}$ & 100 & $\begin{array}{l}\text { Heavy } \\
\text { duty } \\
\text { Truck, } \\
\text { Diesel, } \\
\text { Cooler }\end{array}$ & 100 & $\begin{array}{l}\text { Heavy } \\
\text { duty } \\
\text { Truck, } \\
\text { Diesel, } \\
\text { Cooler }\end{array}$ & 100 \\
\hline
\end{tabular}

Source: authors' creation

\subsubsection{CargoScope: Introducing the Software}

To be usable by non-specialists, models should balance simplicity and usability with analytic power. Developed by CleanMetrics, CargoScope is a web-based tool that allows users to create a supply chain network. Storage, transit and processing parameters can be defined at every echelon. While many websites offer calculators for determining personal carbon footprints, few online tools allow users to configure a business supply chain. CargoScope is selected because it is a low cost solution that allows for specific accounting of utilization and backhaul rates, as well as mode of transportation, level of climate control, and distance travelled. CargoScope's parameters are based on data from U.S. governmental and international agencies; more details are provided at CleanMetric's website (2011) and by Venkat (2007). Users can create, share and revise their models, and CargoScope will calculate the resultant energy and carbon dioxide equivalents emitted. 


\subsubsection{Scenario Results}

Given the information for the four scenarios, CargoScope calculates the emissions that result from the transportation and storage of a kilogram of tomatoes. These results are displayed in Figure 3, a stacked bar chart for each of the transport links and storage echelons. We first note that transportation from the farm is the dominant component in all four scenarios. Likewise, emissions associated with transportation in all stages dwarf those associated with climate control for storage, a finding echoed by Coley et al. (2009).

\section{Fig. 3 - Outbound Logistics Emissions Profiles for Four Initial Sourcing Scenarios}

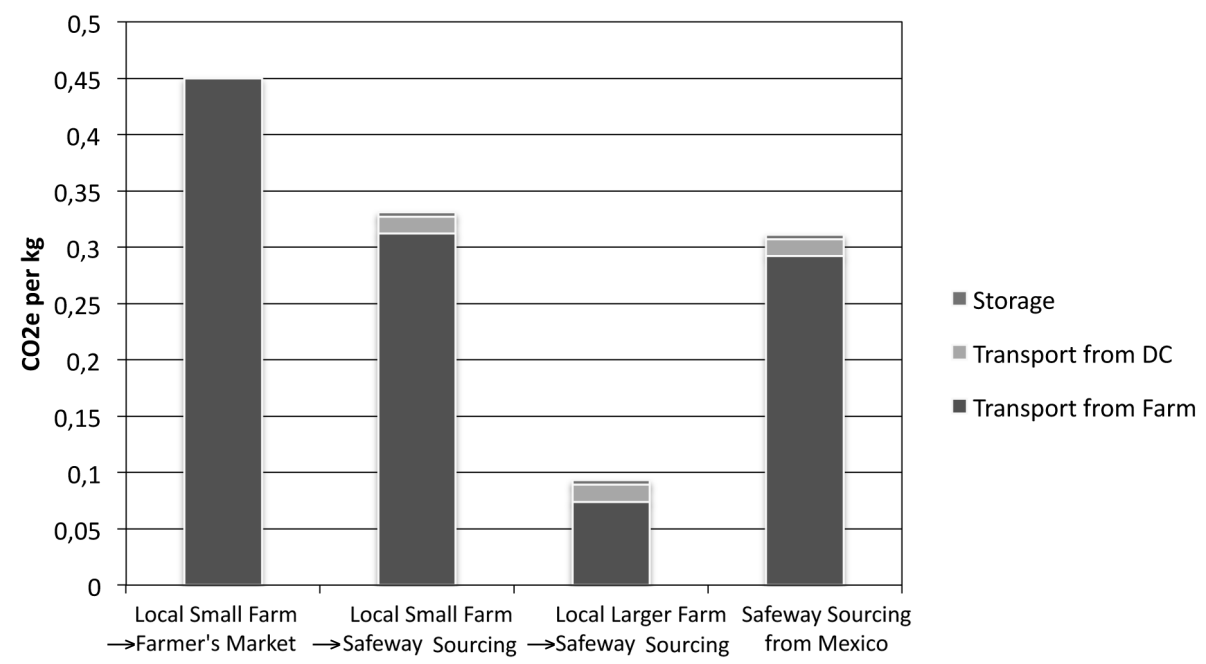

Source: based on CargoScope (2011)

The most emission intensive scenario is that of direct sales to the farmers' market even though it involves the least distance travelled. This result can be attributed to the fact that produce is transported by large pickup truck, a mode that is less efficient than larger vehicles, assuming similar utilization. For example, in CargoScope the fuel usage rate for the midsized truck is approximately 34 liters of diesel for every $100 \mathrm{~km}$ travelled, slightly more than twice that associated with the pick-up truck, at just under 16 liters $/ 100 \mathrm{~km}$. Yet the midsized diesel truck has nearly ten times the cargo capacity of the pickup truck. This discrepancy in vehicular efficiency is illustrated in comparing results between the second and third scenarios, which differ only in how produce is transported from the farm to Safeway's 
distribution center. The efficiencies of scale reported by Coley et al. (2009) and Cantor \& Strochlic (2009), among others, are clearly illustrated here. Even long distance transport from Mexico is more emissions-efficient per kilogram of product than local, small-scale distribution.

\subsection{Modeling the Supply Chain Network}

Given the previous results for one farm, we wish to determine whether these results can be considered representative of the region. We next model the supply chain network for Californian farmers' markets. Figure 1 shows that the market concentration occurs in two distinct regions, suggesting that these regional networks are effectively separable. We limit the scope of the problem to the 135 regularly recurring Bay Area markets and the farmers sourcing them, as found by Jog (2010). While there are 1297 such farmers, we consolidate farms within the same zip code into one representative farm, noting the number of farms comprised by each of these 203 farms. Rather than manually determining the 27,405 potential distances between these farms and their markets, the distances are estimated by a Microsoft Excel add in provided by Spheresoft, which calculates distances between two zip codes. We set a $3 \mathrm{~km}$ distance minimum for the few cases where farms and markets are within the same zip code.

As farmers' markets and farms comprise a bipartite graph, we can formulate a spatially-disaggregated transshipment model of the farmers' market network to illustrate the linkage between sourcing and emissions intensity. Several simplifications and assumptions are necessary for problem tractability. Like Nicholson et al. (2011) we assume a single decision maker, although in reality each farm decides for itself which markets to visit. However, our purpose is to represent at a higher level the weighted distances of goods transported. Also, we consider one single, homogenous good, as do other researchers of large scale models, such as Cruz (2008). We can avoid the use of multiple goods as modeled by Nicholson et al. (2011), since we have no intermediate nodes with transformation processes and since many other fruits and vegetables are similar in density to tomatoes. A real farmers' market sells many types of produce, and supplying tomatoes to one market and apples to another would not provide for sufficient variety. However, we ignore this complication.

We need not only create the network but also model the flow of goods, requiring supply or demand data appropriate to each node. We had previously combined farms within the same zip code; we now assume that all single farms are comparable in size and that the aggregated farm representative of the zip code is a multiple of the number of the single farms found within. We 
simulate a demand distribution for the farmers' markets, assigning them as small, medium or high volume based on a combination of factors: city size, day of occurrence, and proximity to other markets. For instance, the San Francisco Ferry Plaza Market on Saturday would likely generate far more sales than a market in Livermore, especially one that takes place on Thursdays. With these mappings, about half of the markets are small, requiring the equivalent of about pickup truck worth of produce, and 20 markets, $15 \%$ of the total, are considered large. Their demand is set such that they could be effectively serviced by a larger vehicle.

A Government study (Cantor \& Strochlic, 2009) and a trade article (Worthen, 2010), each report that farmers would be willing to sell more of their production through direct sales channels. Such willingness is not surprising, as King et al. (2010) report that farmers capture a much greater percentage of the end retail price through direct channels compared to wholesale. In keeping with these reports we set the aggregate farmers' market demand to be approximately two-thirds of total supply. We should note that while these parametric settings for both supply and demand alike are at best approximations, we are interested in modeling the potential flow through the network as a whole, not in determining details for a particular market or farm.

\subsubsection{Initial Formulation}

We formulate the problem as follows. We define two sets of variables, the kilograms of produce $x_{f m}$ sourced from farm $f$ to serve market $m$, and the number of trucks $s_{f m}$ used to transport produce from farm $f$ to market $m$. Given set $F$ for farms and $M$ for farmers' markets, we seek to minimize the total distance travelled, $z$ :

$$
z=\sum_{f}^{F} \sum_{m}^{M} D I S T_{f, m} * \text { trucks }_{f, m}
$$

We consider the following constraints. First, the farm's supply of produce cannot be exceeded.

$$
S_{f} \geq \sum_{m}^{M} x_{f, m} \forall f \in F
$$

Next, we must meet demand at the farmers' markets. As we make certain that aggregate supply exceeds total demand, this constraint will not render the problem infeasible. 


$$
D_{m}=\sum_{f}^{F} x_{f, m} \forall m \in M
$$

We utilize CargoScope's parameters for all transport modes; the capacity of a pickup truck is set at $600 \mathrm{k}$ g. Tomatoes are dense with high water content; we need consider only weight limits for vehicles as such limits will be more restrictive than volumetric limits.

$$
600 \text { trucks }_{f, m} \geq x_{f, m} \forall f \in F, \forall m \in M
$$

The variable trucks $_{f, m}$ is inherently integer, resulting in a classic mixed integer transportation problem for minimizing the aggregate cost of meeting all demand requirements. With nearly 28000 integer variables, the model is implemented in GAMS with the Gurobi solver and converges on a solution within a $10 \%$ tolerance of the theoretical linear programming optimum in 70 seconds on an E6410 Dell Latitude laptop.

\subsubsection{Summary of Results}

The total aggregate distance travelled from all farms to all markets is just over 70 thousand kilometers and is covered by 683 trucks. Thus, the one-way driving distance averages to $104 \mathrm{~km}$, which represents the low end of the average range of 100 to $300 \mathrm{~km}$ quoted by CUESA (2009). In fact, the largest one-way distance travelled in this solution would be $195 \mathrm{~km}$, when some of the potential distances between farmers and markets are over $400 \mathrm{~km}$. By minimizing aggregate distance in a scenario with excess supply, we essentially cut the more distant farmers out of the market. We reiterate that this solution is an idealized optimization.

This idealization is reflected both on the demand and supply side. For the demand side, one can consider the vendor diversity at each farmers' market at the optimal solution; almost three quarters of the markets would receive visits from at most 2 of the 203 possible suppliers represented. While these suppliers do represent an aggregation of the 1297 farmers certified, an unbundling of the suppliers would result in these smaller markets being serviced by about a dozen separate farmers. The story from the supply side is even more telling; with this optimization more than $40 \%$ of the suppliers would not be granted access to a farmers' market. Furthermore, less than a quarter of the suppliers would be granted access to more than three such markets.

While many of the underrepresented farmers may be closer to Los Angeles or near other markets, the fact that the vast majority of farmers currently sourcing Bay Area markets would be shut out or granted minimal access is 
clearly neither fair nor realistic. This solution should rather be interpreted as the theoretical upper bound on the efficiency possible within the current logistical structure of pickup trucks driving direct from farms to markets. We present this solution because we shall next explore ways of improving this logistical structure, and we wish to measure our improvement against a baseline.

\subsection{An Alternative Logistical Structure}

We investigate the insertion of a consolidation center into the supply chain, where farmers could transport goods, rather than driving them all the way to the farmers' markets. These centers would allow for aggregation with other farmers' offerings over a few days, and then final transportation to the farmers' markets could occur on larger trucks. King et al. (2010) make similar suggestions for improving efficiencies in their analysis of intermediated distribution of local foods, although they do not explicitly consider farmers' markets. This paper addresses only the transportation and storage considerations of such a supply chain option; not financial and other considerations. We assume that farmers would be paid on a consignment basis, prorated for a share in storage, personnel and transport costs.

One of the first considerations for such a center is where to place it. Although locational analysis techniques such as gravity weighting, or even a nonlinear optimization problem could be formulated to determine placement, we invoke more pragmatic considerations. Highway layout and the need for a location near a population center suggest a finite number of realistic warehouse locations. For example, Figure 4 shows a subset of the Northern California farms and farmers' markets with two potential DC/consolidation centers: one in Tracy and one, further south, at Cantua Creek. Jog (2010) studies several locations for such a center and finds that Cantua Creek, a Central Valley town with access to I-5 and several existing warehouses, is a likely candidate.

\subsubsection{Alternative Model Formulation}

To analyze whether the consolidation center increases the efficiency of the distribution network, we must first modify the formulation to include this additional logistical option. Farmers will now be allowed both to transport their produce directly to markets and also to send it to the consolidation center, where it will then be aggregated with others shipments and sent to various farmers' markets, using a larger vehicle than a pickup truck. We 


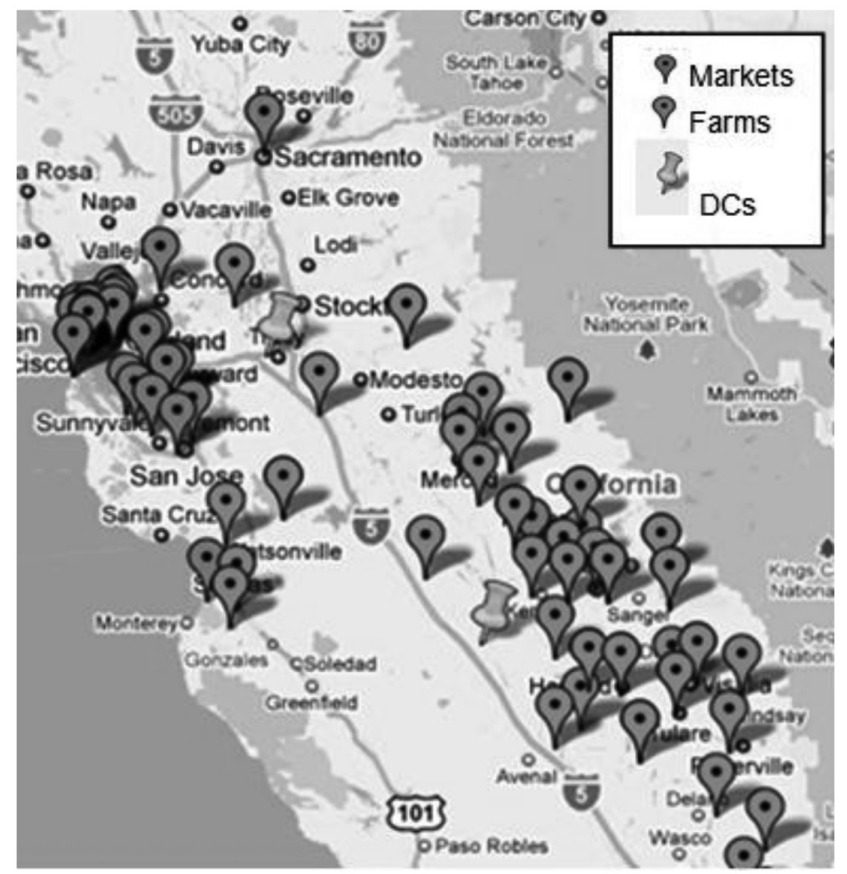

Source: Jog (2010)

select a midsized diesel truck, with an effective cargo limit of $6250 \mathrm{~kg}$ and a higher fuel usage. This vehicle is still much smaller than the heavy-duty trucks that Safeway uses to restock its retail stores, with an effective cargo limit of over 17 thousand kilograms.

With the introduction of an intermediate node, our formulation alters into a more generalized transshipment problem. The modified formulation follows. We must augment our sets of variables; while we still allow for kilograms of produce, $x_{f m}$, sourced from farm $f$ to serve market $m$, and provide trucks $_{f m}$ to transport this produce from farm $f$ to market $m$, we also use trucks to go from farms to the DC, $t f d c_{\mathrm{f}}$ to transport $x f d c_{\mathrm{f}}$ and to go from the DC to markets, $t d c m_{\mathrm{m}}$ to transport $x d c m_{\mathrm{m}}$. Lastly, we need to equate the distance travelled by the midsized trucks servicing the markets from the consolidation center. We must now account for the difference between the carrying capacity and fuel usage between the trucks; the parameter $R$ represents the ratio in fuel usage between these larger vehicles and the pickup trucks used elsewhere. We modify the objective function, $\mathrm{z}$, as follows: 
(5) $z=\sum_{f}^{F} \sum_{m}^{M} D I S T_{f, m} *$ trucks $_{f, m}+\sum_{f}^{F} D I S T_{f} * t f d c_{f}+R * \sum_{m}^{M} D I S T_{m} * t d c m_{m}$

The constraints also require adjustment. As farms can either send produce directly to the market or to the consolidation center, the supply constraint from (2) becomes as follows:

$$
S_{f} \geq \sum_{m}^{M} x_{f, m}+x f d c_{f} \forall f \in F
$$

Likewise market demand can be met either directly from the farm or from the consolidation center, so equation (3) is altered accordingly:

$$
D_{m}=\sum_{f}^{F} x_{f, m}+x d c m_{m} \forall m \in M
$$

The supply into the consolidation center must equal or exceed its output, requiring a new constraint. We assume there is no effective limit on the center's handling capacity:

$$
\sum_{f}^{F} x f d c_{f} \geq \sum_{m}^{M} x d c m_{m}
$$

Lastly, we continue to enforce the capacity limits for all vehicles, where the capacity of a pickup truck is $600 \mathrm{~kg}$ and a midsized truck is $6250 \mathrm{~kg}$, as per CargoScope. As with trucks $s_{f m}$ the variable sets $t d c m_{\mathrm{m}}$ and $t f d c_{\mathrm{f}}$ are defined to be integer.

$$
\begin{aligned}
& 600 * \text { trucks }_{f, m} \geq x_{f, m} \forall f \in F, \forall m \in M \\
& 600 * t f d c_{f} \geq x f d c_{f} \forall f \in F \\
& 6250 * t d c m_{m} \geq x d c m_{m} \forall m \in M
\end{aligned}
$$

\subsubsection{Alternative Model Results}

We can now compare the results the alternate scenario to those from section 2.2.2. First, the consolidation center has a large impact on the flow of produce through the system. The model uses 688 rather than 683 pick-up trucks, but now over $40 \%$ of these trucks (280) drive from farms to the Cantua Creek consolidation center. Only 36 farmers make use of this center, but many of these are high volume producers, and were they able to use larger trucks to transport to the center such savings would be even greater. After the produce reaches Cantua Creek, 31 midsized trucks will transport it to the 20 large farmers' markets and 11 of the medium sized ones. Nearly half $(46 \%)$ of the produce is routed through the consolidation center. 
The new solution results in a total one-way distance of just under 50 thousand kilometers, a $30 \%$ reduction when compared to the baseline optimization. Just under 7 thousand kilometers or $14 \%$ of the total distance driven is from the consolidation center to the markets. As these midsized trucks use about twice as much fuel as pickup trucks, we must apply a multiplier when considering total fuel used and resultant emissions. With this adjustment our new solution still utilizes $19 \%$ less energy than in the baseline scenario.

It should also be noted that a side benefit of a consolidation center is the opportunity for enhanced vendor diversity at the markets. In the baseline scenario, the larger markets are each serviced by between 12 to 14 farmers and the medium markets by between 2 to 7 farmers. With the consolidation center such markets could, in theory, receive goods from each of the 36 producers that deliver to the center. While some of these 36 farmers were larger, a few are small suppliers who would then be able to benefit from expanding their market reach. Such increased diversity would also benefit consumers. The top three desired improvements cited by Alonso and O'Neill's (2011) survey respondents include a yearning for greater variety in both products and vendors.

\section{Proposed Solution}

Comparing the scenario results shows the addition of the consolidation center can lead to significant improvement. At the optimal solution we can decrease the total distance travelled by $30 \%$, improving energy efficiency and resultant emissions by $19 \%$. The savings from utilizing larger trucks echoes the findings from Marquez et al. (2010) in their recommendations for improving the energy efficiency of produce distribution in Victoria, Australia. We even increase vendor diversity at medium and large farmers' markets.

We now return to our original analytic approach from section 2.1 to investigate how such a center would impact Schletewitz Family Farms. We define a fifth scenario that uses the Cantua Creek consolidation center. A Schletewitz employee would drive a pickup truck $95 \mathrm{~km}$ to Cantua Creek, where a midsized truck would then transport their produce and that of others to the San Francisco Farmers' Market, $270 \mathrm{~km}$ distant. We continue the use of $90 \%$ utilization and no backhaul for all vehicles. Figure 5 shows that on a per-kilogram basis, the use of a consolidation center effectively halves the emissions associated with supplying the farmers' market. 
Fig. 5 - Outbound Logistics Emissions Profiles, Now Including a Consolidation Center for Farmers' Markets

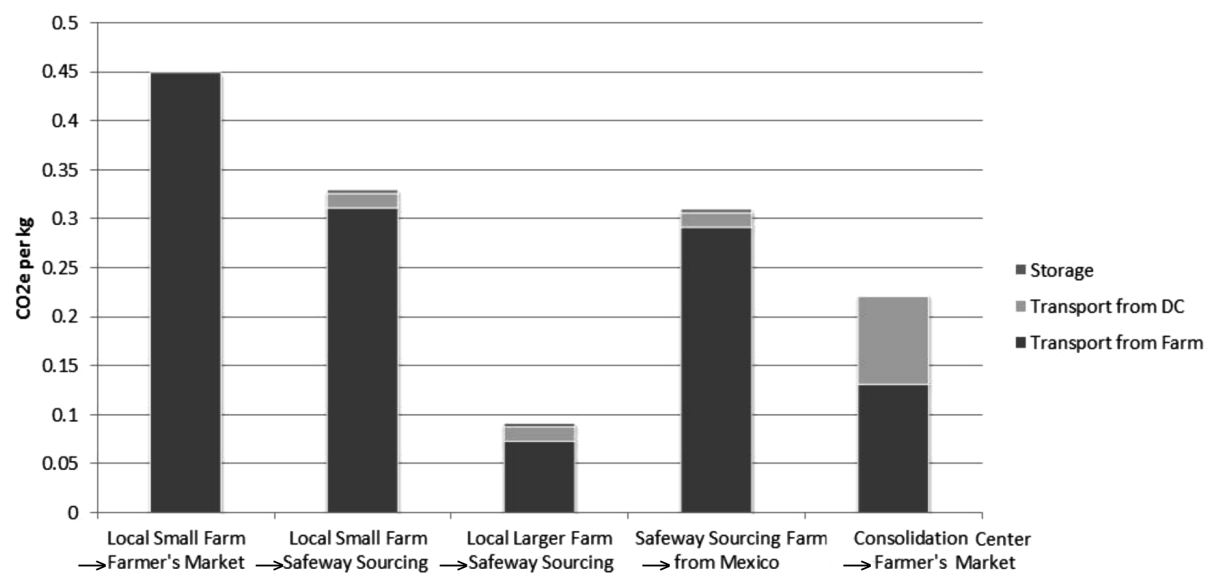

Source: based on CargoScope (2011)

Figure 5 also illustrates that while the emissions from the trek from the Cantua Creek center to the market are significant, they are more than offset by the decreased emissions associated with the transport link from the farm. It should be noted that the efficiency gains modeled come primarily from the substitution of well-utilized midsized trucks for the smaller pickup trucks. This new scenario is the more efficient than all but the third scenario, which assumes a larger scale producer, allowing for the use of more efficient vehicles through the entire supply network. For farmers that are too small to realize any efficiency gains to transporting goods from their farms via larger vehicles, a nearby consolidation center is likely to be a more realistic solution for reducing transport costs and emissions.

It should also be noted that the placement of the distribution center effects efficiency. Although the organizational mechanisms differ, the second and fifth scenarios are similar in their logistical structure, differing primarily in where the intermediate center has been placed and what transport mode is used in transporting to the retail market. Locating a consolidation center closer to the farmer minimizes the distance travelled by the least efficient mode, pickup truck. Thus, we see this last scenario is more energy and emissions efficient than the second scenario. 


\section{Concluding Remarks}

We analyze the energy and resultant emissions necessary to support the current network of Northern Californian farmers' markets. We demonstrate that a consolidation center can result in significant improvements by these metrics, through enabling small farmers to take advantage of previously unavailable economies of scale. In particular, we calculate a $30 \%$ reduction in distance driven and a $19 \%$ improvement in fuel usage over the optimal baseline solution, itself an idealized version of the inefficient network as realized in practice. The profile of Schletewitz Family Farms illustrates that insertion of a consolidation center at Cantua Creek into the supply chain can halve their per kilogram emissions as compared to directly driving to the farmers' market. Instead of being the most energy and emissions intensive configuration, including that of long-distance importation from foreign industrial-scale farms, our alternative farmers' market supply chain would permit this small producer to experience efficiencies typical of larger establishments. In short, such a consolidation center would enable producers and consumers alike to enjoy economies of scale while still retaining the benefits of a system supplied by local family farms.

The solution has several limitations that must be acknowledged. While the placement of farms and markets is based upon real data, the supply and demand volumes have been simulated. For instance, if demand is greater at more of the farmers' markets, the use of additional large vehicles would be justified, suggesting that a consolidation center could rightfully capture an even greater portion of the network traffic. On the other hand, if some farmers have sufficiently large production volumes and a share of a market's sales to justify use of larger vehicles for direct to market deliveries, benefits derived from the consolidation center would be overstated. Refinements to the model could include the consideration of differentiated sales goods, as farms from different areas will likely source different types of produce.

However, before we invest in more data collection or model augmentation, we must consider the substantial practical barriers to our proposed approach. The first barrier is that California farmers' markets are classified as produceronly. The use of consolidation centers would require revising the underlying regulations governing these markets. Such changes would need to be performed delicately and might lead to undesirable repercussions. For instance, opening farmers' markets to a broader participant base could result in food scalpers and other resellers, potentially decreasing product quality and degrading the overall market experience. Other states have fewer restrictions on vendors, so it would behoove policy makers to study if any of these open markets maintain desired marketplace attributes. 
Further investigation would be needed to determine whether such a farmers' market, with a combination of individual and consolidation-center suppliers would be accepted by producers. Some farmers, especially those who are closer to the high value urban markets, might resent a change to the market infrastructure that effectively levels the playing field, negating their inherent geographical advantage. Also, would farmers welcome and take advantage of the opportunity to collaborate? King et al. (2010) examine intermediated supply chains and find that the consolidation stage could be initiated by a variety of agents along the supply chain: retailers, food-service operators, or entrepreneurs, but such action was never initiated by group of producers. Such producer inertia would reduce the efficacy of our proposed solution. Furthermore, consideration of the financial aspects of implementing this solution, including how to collect funds for the improvements, is open to investigation.

Likewise, consumers' potential acceptance would need to be evaluated, as such a solution will likely result in consumers having less personal contact with farmers at the markets. However, this lack of direct interaction may not greatly influence the majority of local food buyers. Zepeda and Li's (2006) extensive survey examines why consumers shop for local foods. Their findings indicate that contact with the farmers is not the main draw, but rather that such foods are perceived by these shoppers as being of superior quality. In her comprehensive review of others' survey results, Brown (2002) shows that quality is the most commonly voiced reason for respondents to shop markets. However, Govindasamy et al. (2002) suggest that direct contact with farmers may play a pivotal part of the buying process, along with produce freshness. Clearly, more market research would be needed.

Although the potential barriers to implementation are formidable, we conclude that such a logistical solution is worth further investigation. Cantor \& Strochlic (2009) posit that consolidation hubs and marketing cooperatives would help farmers in their attempts to compete with larger-scale suppliers in the wholesale market. With respect to direct marketing channels, Cantor \& Strochlic (2009) state that CSA subscriptions sourcing from several farms have proven advantageous. If one such direct-to-consumer channel has gained market acceptance, it seems that there may be opportunities for others. The recent years' expansion of farmers' markets has occurred despite the presence of cooperatives, even in states that do not enforce producer-only rules. Clearly if farmers' markets are to remain a viable and sustainable channel for small Californian family farms in the longer term, the underlying logistics that support them are ripe for improvement. 


\section{References}

Akkerman R., Farahani P., \& Grunow M. (2010), "Quality, Safety and Sustainability in Food Distribution: a Review of Quantitative Operations Management Approaches and Challenges", OR Spectrum, 32(4), pp. 863-904.

Alonso, A.D., \& O’Neill, M.A. (2011), “A Comparative Study of Farmers Markets Visitors Needs and Wants: the Case of Alabama", International Journal of Consumer Studies, 35 (2011), pp. 290-299.

Brown A. (2002), "Farmers Market Research 1940-2000: An Inventory and Review", American Journal of Alternative Agriculture, 17(4), pp. 167-176.

Browne M., Rizet C., Anderson S., Allen J., \& Keïta B. (2005), "Life Cycle Assessment in the Supply Chain: a Review and Case Study", Transport Reviews, 25(6), pp. 761-782.

Brunori G., Guidi F., Neri T., \& Proietti P. (2007), Overview of Innovations Practices in Italy, Available online: www.insightproject.net/files/Italy/WP2_Italy_2007.pdf, Accessed 12 October 2011.

Brunori G., Rossi A., Cerruti R., \& Guidi F. (2009), "Nicchie produttive e Innovazione di Sistema: un'Analisi Secondo l'Approccio delle Transizioni Tecnologiche Attraverso il Caso dei Farmers' Markets in Toscana", Economia agro-alimentare, $\mathrm{XI}(3)$, pp. 143-169.

Cantor A. \& Strochlic R. (2009), "Breaking Down Market Barriers for Small and Midsized Organic Growers", UsDA-AMs: Report 12-25-A-5021.

Carlsson-Kanyama A., Ekström M., \& Shanahan H. (2003), "Food and Life Cycle Energy Inputs: Consequences of Diet and Ways to Increase Efficiency", Ecological Economics, 44(2-3), pp. 293-307.

Carpio C. \& Isengildina-Massa O. (2009), "Consumer Willingness to Pay for Locally Grown Products: the Case of South Carolina", Agribusiness, 25(3), pp. 412-426.

Certified Farmers Market Program (2011), California Department of Food and Agriculture, Available online: www.cdfa.ca.gov/is/i_\&_c/cfm.html, Accessed 15 March 2011.

CleanMetrics (2011), An Energy and Emissions Analyser for Supply Chains, Available online: www.cleanmetrics.net/CargoScope/Info.aspx, Accessed 25 March 2011.

Cholette S. \& Venkat K. (2009), "The Energy and Carbon Intensity of Wine Distribution: a Study of Logistical Options for Delivering Wine to Consumers", Journal of Cleaner Production, 17(16), pp. 1401-1413.

Coley D., Howard M., \& Winter, M. (2009), "Local Food, Food Miles and Carbon Emissions: a Comparison of Farm Shop and Mass Distribution Approaches", Food Policy, 34(2), pp. 150-155.

Conner D., Montri A., Montri D. \& Hamm M. (2009), "Consumer Demand for Local Produce at Extended Season Farmers' Markets: Guiding Farmer Marketing Strategies", Renewable Agriculture and Food Systems, 24(4), pp. 251-259.

Cruz J. (2008), "Dynamics of Supply Chain Networks with Corporate Social Responsibility through Integrated Environmental Decision-Making", European Journal of Operational Research, 184(3), pp. 1005-1031.

CUESA: Center for Urban Education and Sustainable Agriculture (2009), "Issues In a Nutshell", Available online: www.cuesa.org/sustainable_ag/issues/foodtravel.php Accessed 23 March 2011. 
Darby K., Batte M., Ernst S. \& Roe B. (2008), "Decomposing Local: a Conjoint Analysis of Locally Produced Foods", American Journal of Agricultural Economics, 90(2), pp. 476-486.

Giovannuci D., Barham E., \& Pirog R. (2010), "Defining and Marketing 'Local' Foods: Geographical Indications for U.S. Products", The Journal of World Intellectual Property, 10(11), pp. 1747-1796.

Govindasamy R., Italia J., \& Adelaja A. (2002), "Farmers' Markets: Consumer Trends, Prefer-ences, and Characteristics", Journal of Extension, 40(1), pp. 1-7.

Govindasamy R., Italia J., Zurbriggen M. \& Hossain F. (2003), "Producer satisfaction with returns from farmers' market related activity", American Journal of Alternative Agriculture, 18(2), pp. 80-86.

Guthrie J., Guthrie, A., Lawson, R., Cameron A. (2002), "Farmers' markets: the small business counter-revolution in food production and retailing", British Food Journal, 108(7), pp. 560-573.

Greenbiz (2009), "Safeway Expands its Local Food Focus", Available online: www.greenbiz.com/news/2009/06/19/safeway-expands-its-local-food-focus, Accessed 2 April 2010.

Jog S. (2010), Optimizing the Logistics of Farmer's Markets: a Carbon Footprint Study, Master's Thesis, San Francisco State University, California.

Hardesty S. (2008), "Growing Role of Local Food Markets", American Journal of Agricultural Economics, 90(5), pp. 1289-1295.

Heller M. \& Keoleian G. (2000), "Life Cycle-Based Sustainability Indicators for Assessment of the U.S. Food System", [CSS00-04]. Ann Arbor, MI: Center for Sustainable Systems, School of Natural Resources and Environment.

Hunt A. (2007), "Consumer Interactions and Influences on Farmers' Market Vendors", Renewable Agriculture and Food Systems, 22(1), pp. 54-66.

King R.P., Hand M.S., DiGiacomo G., Clancy K., Gómez M.I., Hardesty S.D., Lev L. \& McLaughlin E.W. (2010), "Comparing the Structure, Size, and Performance of Local and Mainstream Food Supply Chains", Report: U.S Department of Agriculture, Economics Research Service.

Kremen A., Greene C. \& Hanson J. (2004), "Organic Produce, Price Premiums, and Eco-Labeling in U.S. Farmers' Markets”, Report No.: VGS-301-01. USDA Economic Research, Service: Washington, DC. Available online: www.ers.usda.gov, Accessed 1 April 2011.

Pirog R., Van Pelt T., Ensayan K. \& Cook E. (2001), Food, Fuel and Freeways: an Iowa Perspective on How Far Food Travels, Fuel Usage, and Greenhouse Gas Emission, Leopold Center for Sustainable Agriculture, Ames, Iowa.

Porjes S. (2007), "Fresh and Local Food in the U.S. Packaged Facts", Rockville MD. Available online: www.ised.us/doc/Packaged\%20FActs\%20Local\%20Foods\%20 (2).pdf, Accessed 1 April 2011.

Marquez L., Higgins A., \& Estrada-Flores S. (2010), Understanding Victoria's Fruit and Vegetable Freight Movements, Victorian Eco-Innovation Lab (VEIL), www.ecoinnovationlab.com/research/food-freight/398-food-freight-understandingvictorias-fruit-and-vegetable-freight-movements Accessed 10 July 2011.

Milà i Canals L., Cowell S., Sim S. \& Basson L. (2007), "Comparing Domestic versus Imported Apples: a Focus on Energy Use", Environmental Science and Pollution Research, 14(5), pp. 338-344.

Nicholson C., Gómez M. \& Gao O. (2011), “The Cost of Increased Localization for a Multiple-Product Food Supply Chain: Dairy in the United States", Food Policy, 36(2), pp. 300-310. 
PA Market (2011), "Schlelteweitz Family Farms", Available online: www.pafarmers market.org/buylocally/schletewitz.htm, Accessed 23 March 2011.

Pacific Coast Farmers' Market directory: PCFMA (2011), Available online: www.pcfma.com/pcfma_resources.php, Accessed 23 March 2011.

Saunders C. \& Barber A. (2007), Comparative Energy and Greenhouse Gas Emissions of New Zealand's and the United Kingdom's Dairy Industry, Lincoln University, Christchurch, New Zealand, No. 297.

Schlich E. \& Fleissner U. (2005), "The Ecology of Scale: Assessment of Regional Energy Turnover and Comparison with Global Food", International Journal of Life Cycle Assessment, 10(3), pp. 219-223.

USDA (2005), Structure and Finances of U.S. Farms: 2005 Family Farm Report, Report EIB-12: Economic Research Service/USDA.

USDA (2011), Farmers' Market Services, Available online: www.ams.usda.gov/ WholesaleFarmersMarkets, Accessed 30 March 2011.

Van Hauwermeiren A., Coene H., Engelen G. \& Mathijs, E. (2007), "Energy Lifecycle Inputs in Food Systems: a Comparison of Local versus Mainstream Cases", Journal of Environmental Policy and Planning, 9(1), pp. 31-51.

Venkat K. (2007), "Analyzing and Optimizing the Environmental Performance of Supply Chains", Proceedings of the ACCEE Summer Study on Energy Efficiency in Industry, U.S. Department of Energy, June 2007, White Plains, New York.

Weber C. \& Matthews H. (2008), "Food-Miles and the Relative Climate Impacts of Food Choices in the United States", Environ Science and Technology, 42(10), pp. 3508-3513.

Worthen B. (2010), "Farmers Markets See Risk from Growth", Wall Street Journal, 10 February 2011, Available online: http://online.wsj.com/article/SB10001424052 748704533204575048000839268376.html\#articleTabs\%3Darticle, Accessed 2 April 2010.

Zepeda L. \& Leviten-Reid C. (2004), “Consumers' Views on Local Food”, Journal of Food Distribution Research, 35(3), pp. 1-6.

Zepeda L. \& Li J. (2006), “Who Buys Local Food?" Journal of Food Distribution Research, 37(3), pp. 1-11.

\section{Summary}

Addressing the greenhouse gas emissions associated with food distribution: a case study of Californian farmers' markets

American consumers' growing taste for locally produced food has resulted in the proliferation of farmers' markets in the U.S. While benefits abound, the very success of these markets has created an inefficient network; farmers drive long distances with small cargos multiple times each week. Not only does this increase costs, but on a per unit basis, the energy usage and resultant greenhouse gas emissions associated with supplying farmers' markets can be greater than those associated with the equivalent supermarket distribution.

In this case study, we investigate the outbound journey of food from a farm to a farmers' market and compare it to corresponding conventional journeys, finding 
farmers' market distribution indeed produces greater emissions. We then model Northern California's farmers' market network, solving a mixed integer transportation problem to quantify the aggregate distance travelled.

We next insert a consolidation center. Farmers can transport goods either directly to the market or to this center for aggregation with other farmers' offerings. Solving the new model shows that significant savings are possible. While admittedly rife with implementation barriers, such a solution could allow small farmers to profit from economies of scale while still retaining their independence and preserving the diversity of the markets. We view this study as a first step towards reworking the system to enable consumers and producers alike to enjoy the benefits of farmers' markets while reducing costs and greenhouse gas emissions.

JEL Codes: $Q 1, Q 5, R 4$

Key words: farmers' markets, greenhouse gas emissions, network optimization, supply chains, distribution

Corresponding Author: Susan Cholette - Associate Professor - Department of Decision Sciences, San Francisco State University, 1600 Holloway Avenue, San Francisco, California - 94132 USA, ph. ++1.415.405-2173 - e-mail: Cholette@sfsu.edu 
Per la valutazione degli articoli pubblicati nei Numeri 1, 2 e 3 del 2011, la rivista Economia agro-alimentare si è avvalsa dei seguenti Referee. A tutti loro, vanno i più vivi ringraziamenti del Comitato e della Segreteria di Redazione.

Felice Adinolfi (Alma Mater Studiorum Università di Bologna), Lucia Baldi (Università degli Studi di Milano), Angelo Belliggiano (Università degli Studi del Molise), Gianluca Brunori (Università di Pisa), Luca Camanzi (Alma Mater Studiorum Università di Bologna), Maurizio Canavari (Alma Mater Studiorum Università di Bologna), Roberta Capitello (Università degli Studi di Verona), Domenico Carlucci (Università degli Studi di Bari "Aldo Moro"), Giuseppina Carrà (Università degli Studi di Catania), Gian Paolo Cesaretti (Università degli Studi di Napoli "Parthenope"), Gianni Cicia (Università degli Studi di Napoli "Federico II"), Pietro Columba (Università degli Studi di Palermo), Maria Crescimanno (Università degli Studi di Palermo), Paolo Cupo (Università degli Studi di Napoli “Federico II"), Edi Defrancesco (Università degli Studi di Padova), Adele Finco (Università Politecnica delle Marche), Roberto Furesi (Università degli Studi di Sassari), Antonino Galati (Università degli Studi di Palermo), Claudio Malagoli (Università degli Studi di Scienze Gastronomiche), Giulio Malorgio (Alma Mater Studiorum Università di Bologna), Edoardo Marcucci (Università degli Studi Roma Tre), Nicola Marinelli (Università degli Studi di Firenze), Giuseppe Marotta (Università degli Studi del Sannio), Christine Mauracher (Università Ca' Foscari Venezia), Silvio Menghini (Università degli Studi di Firenze), Erika Pignatti (Alma Mater Studiorum Università di Bologna), Alberto Pirani (Università degli Studi di Milano), Carlo Pirazzoli (Alma Mater Studiorum Università di Bologna), Sonia Prestamburgo (Università degli Studi di Trieste), Pietro Pulina (Università degli Studi di Sassari), Severino Romano (Università degli Studi della Basilicata), Luca Rossetto (Università degli Studi di Padova), Carlo Russo (Università degli Studi di Cassino), Massimo Sabbatini (Università degli Studi di Cassino), Andrea Salghetti (Università degli Studi di Parma), Antonio Seccia (Università degli Studi di Bari “Aldo Moro”), Giovanni Signorello (Università degli Studi di Catania), Roberta Spadoni (Alma Mater Studiorum Università di Bologna), Samuele Trestini (Università degli Studi di Padova), Giovanna Trevisan (Università Ca' Foscari Venezia). 